\title{
OLIMPIADA NACIONAL DE HISTORIA DEL BRASIL - ONHB: MÁS ALLÁ DE LA COMPETICIÓN, LA COOPERACIÓN Y LA EDUCACIÓN CONTINUA
}

\author{
José Gerardo Bastos Costa Júnior
}

gerardo.junior@ifrn.edu.br

http://orcid.org/0000-0002-8428-2281

Francisco Das Chagas Silva Souza

chagas.souza@ifrn.edu.br

https://orcid.org/0000-0002-9721-9812

Instituto Federal de Educação, Ciência e Tecnologia do Rio Grande do Norte (IFRN)

Campus Mossoró, Brasil.

Recibido: 2020-07-27; Aceptado: 2020-11-11

\section{Resumen}

En este artículo, presentamos las Olimpiadas Nacionales de Historia de Brasil (ONHB), promovidas desde 2009 por la Universidad de Campinas (UNICAMP), Brasil. Además, destacamos el potencial de este evento para el proceso de enseñanza-aprendizaje de la Historia en la Educación Básica, así como para la formación continua de los profesores de esta disciplina. La investigación se basó en la revisión bibliográfica y la investigación exploratoria en el sitio de la ONHB, donde se pueden encontrar documentos, pruebas y toda la información sobre el evento. La bibliografía, los contenidos de la página web de la ONHB y nuestra experiencia en la participación en varias ediciones nos llevan a concluir que esta Olimpiada científica contribuye al desarrollo profesional de los profesores de Historia, ya que tienen acceso a nuevas fuentes, viven experiencias, realizan investigaciones e intercambian conocimientos con otros profesores y sus equipos, produciendo articulaciones entre el saber y el hacer, es decir, entre la teoría y la práctica. Así, destacamos que la ONHB no es sólo una simple competición, sino también un espacio de colaboración y formación de estudiantes y profesores.

Palabras clave: ONHB. Formación de profesores. La enseñanza de la historia.

\section{OLIMPÍADA NACIONAL EM HISTÓRIA DO BRASIL: PARA ALÉM DA COMPETIÇÃO, A COOPERAÇÃO E A FORMAÇÃO CONTINUADA}

\section{Resumo}

Neste artigo, apresentamos a Olimpíada Nacional em História do Brasil (ONHB), promovida, desde 2009, pela Universidade de Campinas (Unicamp), Brasil. Ademais, realçamos a potencialidade desse evento para o processo de ensino-aprendizagem de História na Educação Básica, e ainda para a formação continuada de professores dessa disciplina. A investigação se deu a partir de revisão bibliográfica e de pesquisa exploratória no site da ONHB, onde se encontram documentos, provas e todas as informações acerca do evento. A bibliografia, o conteúdo do site da ONHB e a nossa experiência na participação em várias edições nos leva a concluir que essa Olimpíada científica contribui para o desenvolvimento profissional de professores de História, visto que estes têm acesso a novas fontes, vivenciam experiências, realizam pesquisas e trocas de conhecimentos com outros docentes e com suas equipes, 
produzindo articulações entre o saber e o fazer, ou seja, entre teoria e prática. Dessa forma, ressaltamos que a ONHB não é apenas uma simples competição, mas também um espaço de colaboração e de formação de alunos e professores.

Palavras-chave: ONHB. Formação docente. Ensino de História.

\title{
NATIONAL OLYMPIC IN BRAZILIAN HISTORY: BEYOND COMPETITION, COOPERATION AND CONTINUING EDUCATION
}

\begin{abstract}
In this article, we present the National Olympics in Brazilian History (ONHB), promoted since 2009 by the University of Campinas (Unicamp), Brazil. In addition, we highlight the potential of this event for the teaching-learning process of History in Basic Education, as well as for the continued training of teachers of this discipline. The investigation was based on bibliographic review and exploratory research in the ONHB site, where documents, evidence and all information about the event can be found. The bibliography, the contents of the ONHB website and our experience in participating in several editions lead us to conclude that this scientific Olympiad contributes to the professional development of History teachers, since they have access to new sources, live experiences, carry out researches and exchange knowledge with other teachers and their teams, producing articulations between knowledge and doing, that is, between theory and practice. Thus, we emphasize that the ONHB is not only a simple competition, but also a space of collaboration and formation of students and teachers.
\end{abstract}

Keywords: ONHB. Teacher training. History teaching.

\section{Introdução}

Nas últimas décadas, no Brasil, têm se ampliado a realização de olimpíadas científicas escolares, muitas das quais de alcance internacional e promovidas com financiamento do Governo Federal. Em algumas dessas competições, os estudantes mais bem classificados podem participar de programa de iniciação científica júnior, com bolsas do Conselho Nacional de Desenvolvimento Científico e Tecnológico (CNPq). Porém, é importante frisar que muitas dessas competições ocorrem também em níveis local, estadual e regional, sendo sempre percebidas como práticas viáveis para a melhoria da aprendizagem, haja vista a motivação que gera nos alunos e professores participantes.

Neste artigo, abordamos a Olimpíada Nacional em História do Brasil (ONHB), criada em 2009 e organizada pela Universidade de Campinas (Unicamp). De acordo com o sítio desse evento $^{1}$, a partir de 2018, a ONHB se tornou um projeto de extensão do Departamento de História da referida Universidade e contou, em alguns anos, com apoio do Ministério da Ciência, Tecnologia, Inovações e Telecomunicações (MCTIC), por meio do edital de

\footnotetext{
${ }^{1}$ https://www.olimpiadadehistoria.com.br/
} 
Olimpíadas Científicas do Conselho Nacional de Desenvolvimento Científico e Tecnológico (CNPq).

Ao longo dos seus onze anos de história, a ONHB tem apresentado números elevados de participantes. Um exemplo disso é o quantitativo de equipes inscritas em 2019: mais de 18 mil, equivalendo um total aproximado de 55 mil estudantes de todos os estados do Brasil, além de milhares de professores orientadores.

Considerando esses números e a realização do evento anualmente, por mais de uma década, objetivamos, neste artigo, apresentar a ONHB no seu caráter operacional (organização, metodologias utilizadas na aplicação e avaliação das provas, dentre outros aspectos) e expor a potencialidade dessa Olimpíada para a formação continuada de professores de História nela envolvidos. Compreendemos que, com tal discussão, podemos contribuir para o debate acerca da participação de alunos e escolas em competições científicas, algo criticado por muitos pesquisadores, como veremos adiante.

As fontes de informação e análise dos resultados que possibilitaram a escrita deste texto foram de caráter bibliográfico (artigos e obras que tratam do ensino de História e da formação de professores dessa disciplina) e documental (provas, regulamentos, tarefas etc. disponíveis no site da ONHB).

Portanto, este artigo resulta de uma investigação de natureza qualitativa, a qual, de acordo com Chizzotti (2000, p. 79), “[...] parte do fundamento de que há uma relação dinâmica entre o mundo real e o sujeito, uma interdependência viva entre o sujeito e o objeto, um vínculo indissociável entre o mundo objetivo e a subjetividade do sujeito [grifo nosso]". Não podemos deixar de destacar, como afirmou Chizzotti, a relação de interdependência entre nós, pesquisadores e professores participantes da ONHB, e nossa implicação no objeto da pesquisa, o evento. Por isso, ressaltamos o cabedal de experiências que acumulamos com o nosso envolvimento em dez edições da ONHB, exercendo as funções de professores orientadores de equipes, preparando previamente os estudantes para as tarefas, realizando atividades análogas àquelas que fazem parte do evento, promovendo encontros presenciais durante a competição, debatendo as questões e as tarefas, mas, ao mesmo tempo, proporcionando aos estudantes a autonomia na tomada de decisões. Logo, neste artigo não nos prendemos apenas às referências bibliográficas, mas também ao fato de experienciarmos “por 
dentro" as atividades desenvolvidas na ONHB em face de uma década de participação nesse evento.

Este artigo está dividido em duas seções. Na primeira, discutimos as olimpíadas científicas considerando as polêmicas que existem em relação ao seu aspecto de competição e/ou de colaboração. Na segunda, apresentamos a ONHB observando a organização desse evento, a metodologia empregada, a tipologia das provas, a avaliação final. Posteriormente, debatemos a possibilidade dessa competição contribuir para a formação do professor de História.

\section{Olimpíadas científicas: competição, colaboração ou motivação?}

No Brasil, é cada vez mais crescente o número de olimpíadas científicas nas mais diversas áreas do conhecimento. Como exemplos, temos as olimpíadas de Astronomia, Biologia, Física, Informática, Geografia, Linguística, Matemática, Química, Robótica, Saúde e Meio Ambiente, Língua Portuguesa, Oceanografia, História do Brasil, Ciências, Cartografia, Biodiversidade e Ciências da Vida, dentre outras. Muitas destas são nacionais, mas há também as estaduais e regionais. Algumas recebem financiamento do Conselho Nacional de Desenvolvimento Científico e Tecnológico ( $\mathrm{CNPq}$ ), órgão que considera as olimpíadas científicas como:

[...] momentos privilegiados para a divulgação científica e para a descoberta e incentivo de novos talentos. O caráter competitivo estimula a inventividade dos alunos e professores, além de fornecer elementos fundamentais ao Ministério da Educação para avaliar os estudantes brasileiros em relação aos alunos de outros países. Como benefício adicional, muitas olimpíadas incentivam o trabalho em equipe, reforçando hábitos de estudo, o despertar de vocações científicas e os vínculos de cooperação entre equipes de estudantes e professores (Conselho Nacional de Desenvolvimento Científico e Tecnológico [CNPq], 2015).

No site do CNPq é possível encontrarmos chamadas de financiamento de olimpíadas científicas nacionais e internacionais. Em 2019, por meio da Chamada CNPq/MCTIC N 13/2019, o governo brasileiro disponibilizou R $\$ 2.000 .000,00$ (dois milhões de reais) para despesas de custeio (Conselho Nacional de Desenvolvimento Científico e Tecnológico, 2019). Essa Chamada apresentava como objetivos: 
Apoiar a realização de Olimpíadas Científicas de âmbito nacional como instrumento de popularização da ciência e melhoria dos ensinos fundamental e médio, para identificar jovens talentosos que possam ser estimulados a seguir carreiras técnico-científicas e docente. Poderá ser apoiada também a realização de Olimpíadas Científicas Internacionais no Brasil [...]. As Olimpíadas Científicas devem procurar aderência aos seguintes objetivos específicos:

I. Estimular os jovens alunos da rede de ensino, para as carreiras ligadas às áreas científicas, tecnológicas e docente.

II. Fortalecer habilidades dos professores, pesquisadores, técnicos e alunos da Educação Básica.

III. Incentivar a aproximação entre escolas, instituições de ensino e pesquisa e a comunidade.

IV. Incrementar o ensino da ciência na Educação Básica das escolas em todo o País, buscando o letramento científico.

V. Promover a troca de experiências entre os estudantes das escolas, incentivando a competitividade saudável que permita o desenvolvimento e a descoberta de novos talentos.

VI. Estimular o uso do conhecimento científico como ferramenta empoderadora e de transformação social, buscando a diminuição das desigualdades sociais e da melhoria da qualidade de vida da população em geral (Conselho Nacional de Desenvolvimento Científico e Tecnológico [CNPq], 2019, p. $1)$.

Entretanto, mesmo que as intenções pareçam louváveis e que recebam o apoio de muitos pesquisadores e professores brasileiros, alguns estudos fazem críticas contundentes às olimpíadas científicas ao destacar o incentivo à competitividade que estas geram entre escolas e estudantes. Dentre esses pesquisadores destacamos Rezende e Ostermann (2012). Para elas, “As olimpíadas escolares de qualquer disciplina se espelham nas competições esportivas mundiais que visam à seleção de vencedores e, consequentemente, de perdedores nas diversas modalidades de esporte" (2012, p. 248). Assim, de acordo com as autoras, semelhante às competições esportivas entre os países, as olimpíadas científicas passam a imagem que todos os alunos e escolas estão concorrendo de modo igual, escamoteando as desigualdades sociais e regionais.

As autoras em tela assinalam que as olimpíadas científicas são sustentadas pela finalidade dos cientistas em encontrar novos talentos - perceba-se essa palavra nos objetivos da Chamada do CNPq de 2019 - para incrementar os quadros científicos do país, portanto, responde aos anseios da política desenvolvimentista do governo brasileiro nas últimas 
décadas. Rezende e Ostermann (2012, p. 249) criticam o modelo de educação preocupado em "caçar" talentos:

A mentalidade que defende as olimpíadas científicas parece pautar-se na ideia de que a construção do conhecimento científico baseia-se na contribuição de talentos individuais. Este aspecto está cada vez mais questionado nas narrativas epistemológicas contemporâneas que veem a construção da ciência como coletiva e distribuída. Também a aprendizagem é cada vez mais aceita como um processo eminentemente social. A perspectiva sociocultural vem enfatizando seu caráter mediado por outros indivíduos e pela linguagem. Isso não quer dizer que o indivíduo não se desenvolva ou possa aprender sozinho, mas que precisa de algum tipo de mediação, exercida por um material ou por outro indivíduo. Além de possibilitar aprendizagem efetiva, a interação e a colaboração são valores defensáveis tanto do ponto de vista cognitivo ou educativo quanto do ponto de vista da formação humana.

As autoras indagam: "Por que defender a competição entre alunos ou entre escolas? Qual seria o princípio educativo que possibilitaria defender a disseminação do espírito competitivo?", e, em seguida, afirmam: "Na realidade, se pensarmos na escola tal como ela vem se desenvolvendo desde o século XVIII, a partir de seus laços íntimos com o sistema capitalista, as olimpíadas escolares parecem uma proposta educativa "coerente" (Rezende \& Ostermann, 2012, p. 251).

Outra crítica às competições escolares (embora não se refira às olimpíadas) é feita por Dubet (2004) em um artigo cujo título nos estimula à reflexão: “O que é uma escola justa?”. Nesse texto, salienta a complexidade do que seja uma escola justa em uma sociedade marcada pela desigualdade. O autor afirma que, ao contrário das sociedades aristocráticas que priorizavam o nascimento, “[...] as sociedades democráticas escolheram convictamente o mérito como um princípio essencial de justiça: a escola é justa porque cada um pode obter sucesso nela em função de seu trabalho e de suas qualidades” (2004, p. 541). No entanto, observa que o modelo meritocrático está longe de se realizar, haja vista que a competição não é perfeitamente justa, pois “[...] quanto mais favorecido o meio do qual o aluno se origina, maior sua probabilidade de ser um bom aluno, quanto mais ele for um bom aluno, maior será sua possibilidade de aceder a uma educação melhor, mais diplomas ele obterá e mais ele será favorecido". Diante disso, o autor destaca um dos maiores problemas causados pela meritocracia: 
[...] é importante sublinhar uma certa crueldade do modelo meritocrático. Na verdade, quando adotamos o ideal de competição justa e formalmente pura, os "vencidos", os alunos que fracassam, não são mais vistos como vítimas de uma injustiça social e sim como responsáveis por seu fracasso, pois a escola lhes deu, a priori, todas as chances para ter sucesso como os outros [grifo nosso]. A partir daí, esses alunos tendem a perder sua auto-estima, sendo afetados por seu fracasso e, como reação, podem recusar a escola, perder a motivação e tornar-se violentos. A seu ver, a escola meritocrática atraiu-os para uma competição da qual foram excluídos; eles acreditaram na vitória e na igualdade de oportunidades e descobrem suas fraquezas, sem o consolo de poder atribuir o fato às desigualdades sociais, das quais não são mais diretamente vítimas. Do ponto de vista dos professores, a escola meritocrática também é cruel, pois a escola se torna o principal agente de seleção escolar e social, tomando as decisões de orientação que a sociedade abdica de tomar, na contracorrente da escolaridade. Assim, e independentemente do que pensam os atores, a escola meritocrática legitima as desigualdades sociais (Dubet, 2004, p. 543).

Não obstante às críticas referentes às olimpíadas do conhecimento, encontramos também pesquisadores que defendem os aspectos positivos dessas competições no que diz respeito ao desenvolvimento das aprendizagens dos estudantes participantes. Como exemplos podemos destacar Quadros et al (2013) que relatam investigações realizadas sobre a participação de docentes e discentes na Olimpíada Mineira de Química (OMQ). Os autores concluem que:

As olimpíadas científicas também podem representar uma oportunidade de diversificar as ferramentas de ensino, de ampliar as discussões em sala de aula e de inserir novos temas nessas discussões. O ambiente olímpico é de competição, assim como são competitivas algumas etapas de vida. Como professores, temos que lidar e ensinar nossos estudantes a lidarem com eventuais deslizes nessas etapas da vida. E quando o sucesso é alcançado na sala de aula, colaborar para que outros também o alcancem é função não só do professor, mas de todos que compõem o ambiente de sala de aula. Afinal, a escola prepara cidadãos! (Quadros et al., 2013, p. 161).

Também nessa direção, Meneguello (2015), do Instituto de Filosofia de Ciências Humanas (IFCH) da Unicamp e coordenadora da ONHB, ao ser indagada em uma entrevista no tocante aos estudos que realçam a exclusão de alunos de escolas públicas nas olimpíadas, posicionou-se da seguinte forma:

Discordo completamente de que as olimpíadas possam gerar exclusão ou qualquer malefício no sistema de aprendizagem. Observamos que 
as críticas vêm de pessoas de dentro da academia que só falam teoricamente do ensino básico e, geralmente, não entendem o que são as olimpíadas e nem os seus benefícios. Diversos trabalhos apresentados em eventos que participamos comprovam que, mais do que o trabalho durante a sala de aula, deve-se incentivar o que o aluno vai fazer depois ou antes, como o clube de astronomia, uma visita ao museu ou mostra científica e também as olimpíadas, porque é no ensino paralelo que o aluno realmente desabrocha. Ser contra esse ensino extraclasse é estar desatualizado no que há de mais importante no ensino e aprendizagem.

Dessa forma, tanto Quadros et al quanto Meneguello consideram que os professores participantes de eventos olímpicos percebem uma melhor aprendizagem por parte dos seus alunos, inclusive, para além dos conteúdos escolares; e uma maior participação nas aulas em suas disciplinas. Ademais, sustentam a importância destas para a diversificação dos instrumentos metodológicos de ensino.

Rodrigo (2012, p. 2) afirma que: “Além de ganhar medalhas, prêmios e certificados, os participantes vencedores tornam-se alvos de disputas pelas melhores instituições nacionais e estrangeiras, que reconhecem a qualidade do conhecimento adquirido durante esses eventos". Para ele, "O desafio proposto por essas competições motiva discentes, professores e escolas, sem contar as famílias dos estudantes. Esses eventos se tornaram um celeiro de futuros grandes pesquisadores".

Apesar de Rodrigo (2012) ser favorável às olimpíadas científicas escolares, é interessante ressaltar que, de certa forma, as suas observações podem ser interpretadas tanto como um reconhecimento dos aspectos positivos nas olimpíadas do conhecimento como, dependendo do ponto de vista, também podem ir ao encontro das críticas feitas por Rezende e Ostermann (2012) e por Dubet (2004), no que diz respeito ao modelo competitivo e meritocrático, haja vista a importância que ele dá às disputas entre as instituições, por novos talentos.

Na seção seguinte, apresentamos uma das maiores olimpíadas científicas do Brasil, a Olimpíada Nacional em História do Brasil (ONHB).

\section{Olimpíada Nacional em História do Brasil: potencial formativo}

Como já informamos anteriormente, a ONHB foi criada em 2009 e é um projeto de extensão da Universidade de Campinas (Unicamp), Brasil, tendo recebido, em alguns anos, 
financiamento do Governo Federal por meio das chamadas do Ministério da Ciência, Tecnologia, Inovações e Telecomunicações (MCTIC).

A participação da ONHB não é individual, como em diversas outras olimpíadas. Para se inscrever, é necessária a formação de uma equipe composta por três estudantes da Educação Básica (a partir do oitavo ano do Ensino Fundamental), das esferas pública ou privada de ensino, e mais um professor orientador, podendo este coordenar outras equipes. Na Tabela 1, apresentamos o quantitativo de equipes compostas por estudantes e professores de História que participam da ONHB nos dez anos de sua existência.

Tabela 1

\begin{tabular}{|c|c|c|}
\hline Edição & Ano & Número \\
\hline $\mathbf{1}^{\mathrm{a}}$ & 2009 & $4.000^{\mathrm{a}}$ \\
\hline $2^{a}$ & 2010 & 13.268 \\
\hline $3^{a}$ & 2011 & 16.519 \\
\hline $4^{a}$ & 2012 & 10.785 \\
\hline $5^{a}$ & 2013 & 10.391 \\
\hline $6^{a}$ & 2014 & 9.997 \\
\hline $7^{a}$ & 2015 & 10.251 \\
\hline $8^{a}$ & 2016 & 10.719 \\
\hline $9^{a}$ & 2017 & 12.028 \\
\hline $10^{a}$ & 2018 & 14.387 \\
\hline $11^{\mathrm{a}}$ & 2019 & 18.505 \\
\hline
\end{tabular}

Nota. Fonte: Dados obtidos no site da ONHB.

${ }^{a}$ Estimativa a partir do número de estudantes e professores inscritos na $1^{\mathrm{a}}$ edição da ONHB.

Em termos de organização e desenvolvimento da ONHB, esse evento era, até a sua nona edição, em 2017, dividido em cinco fases de provas on line e uma final e presencial com premiação. Contudo, a partir da décima edição, em 2018, foi acrescida uma sexta etapa virtual. A primeira e a segunda fases têm dez questões de múltipla escolha e uma tarefa que as equipes deverão desenvolver. Nas terceira e quarta fases há o acréscimo de mais uma questão e uma tarefa. Na quinta fase, as equipes deverão construir um texto conforme as orientações da Comissão Organizadora. Esses textos posteriormente serão avaliados, na sexta etapa, pelas equipes classificadas com base nos critérios estabelecidos pela organização da olimpíada. 
$\mathrm{Na}$ fase final, presencialmente na Unicamp, as equipes melhor posicionadas nas fases virtuais (entre 200 e 300, garantindo a representação de todos os estados em que houve inscritos) respondem a uma prova com questões discursivas. Este exame vem sendo estruturado de diferentes formas: o estudo de uma obra de um autor renomado na historiografia brasileira (como nas três primeiras edições da ONHB); ou baseada em um determinado tema, como vem ocorrendo desde 2012. Após a avaliação, a comissão organizadora da ONHB distribui medalhas a todas as equipes finalistas, de acordo com a soma de pontos das fases on line com a prova final. São 15 de ouro, 25 de prata, 35 de bronze e o restante recebe medalha de menção honrosa (chamada pela organização de medalha de cristal), além de certificados de participação e desempenho.

Importa destacar que embora a ONHB não seja um evento pautado em uma prova temática, desde a sua primeira edição, em 2009, a Comissão Organizadora elege um assunto que perpassa por várias questões da prova, como apresentamos na Tabela 2:

\section{Tabela 2}

\section{Temas abordados na ONHB (2009-2019)}

\begin{tabular}{cll}
\hline Edição & Ano & Tema \\
\hline $\mathbf{1}^{\mathbf{a}}$ & $\mathbf{2 0 0 9}$ & Documento e monumento \\
$\mathbf{2}^{\mathbf{a}}$ & $\mathbf{2 0 1 0}$ & História oral \\
$\mathbf{3}^{\mathbf{a}}$ & $\mathbf{2 0 1 1}$ & Patrimônio industrial \\
$\mathbf{4}^{\mathbf{a}}$ & $\mathbf{2 0 1 2}$ & Combates e embates em suas diversas expressões \\
$\mathbf{5}^{\mathbf{a}}$ & $\mathbf{2 0 1 3}$ & A conformação étnica do Brasil \\
$\mathbf{6}^{\mathbf{a}}$ & $\mathbf{2 0 1 4}$ & 50 anos do Golpe Civil-Militar de 1964 e seus desdobramentos \\
$\mathbf{7}^{\mathbf{a}}$ & $\mathbf{2 0 1 5}$ & O preconceito e suas muitas manifestações ao longo da história do Brasil \\
$\mathbf{8}^{\mathbf{a}}$ & $\mathbf{2 0 1 6}$ & Escola, lugar de história \\
$\mathbf{9}^{\mathbf{a}}$ & $\mathbf{2 0 1 7}$ & Ensinar e aprender História \\
$\mathbf{1 0}^{\mathbf{a}}$ & $\mathbf{2 0 1 8}$ & As relações entre as leis, a justiça, os direitos e a cidadania \\
$\mathbf{1 1}^{\mathbf{a}}$ & $\mathbf{2 0 1 9}$ & Os excluídos da História \\
\hline
\end{tabular}

Nota. Fonte: Dados obtidos no site da ONHB.

$\mathrm{O}$ fato de os inscritos na ONHB serem organizados em equipes e terem seis dias para responder cada fase virtual, oportuniza a cooperação e a parceria entre os estudantes e os professores. Conforme experenciamos enquanto docentes orientadores, durante esses dias, todos os participantes realizam, em grupos, leitura das questões e pesquisam com vistas a ampliar os conhecimentos e chegar ao item considerado mais "pertinente" como resposta a uma das quatro assertivas (A, B, C, D) das questões das provas. Essas alternativas de resposta têm diferentes valores $(0,1,4,5)$ e se relacionam aos níveis de compreensão do processo 
histórico, referentes aos conteúdos e às fontes pesquisadas e analisadas. Conforme Miranda (2015, p. 81), “A ONHB considera que a alternativa de nível descritivo corresponderia a ' 1 ' ponto; a de nível de explicação simples corresponderia a '4' pontos; a de explicação em contexto, [...] equivalendo a '5' pontos". Quanto à pontuação “0”', esta se destina àqueles casos em que os estudantes assinalam a alternativa que indica anacronismo ou incoerência analítica.

Esse formato, que segue uma metodologia de execução e avaliação específica, é um diferencial para que as equipes não se restrinjam apenas a uma possibilidade de resposta. Espera-se que, assim, os estudantes se sintam estimulados e motivados a uma pesquisa com maior profundidade. Portanto, mesmo que assinalem o item com a menor pontuação, sua interpretação e compreensão não são desconsideradas (Negócio \& Lima-Neto, 2018).

No tocante ao conteúdo das provas, Meneguello (2011), coordenadora da ONHB, afirma que o evento segue os Parâmetros Curriculares Nacionais do Ministério da Educação (MEC), organizados para os Ensinos Fundamental e Médio. Ressaltou que os documentos oficiais exigem a aquisição de competências cognitivas e socioafetivas do ensino de História, dentre as quais, destaca, com base nas Diretrizes Curriculares Nacionais para o Ensino Médio (DCNEM), a autonomia intelectual e a construção do pensamento crítico; as capacidades de aprender e de elaborar significados sobre a realidade social e política; e a "compreensão do processo de transformação da sociedade e da cultura e o domínio dos princípios e fundamentos científico-tecnológicos para a produção de bens, serviços e conhecimentos, relacionados à disciplina histórica" (Meneguello, 2011, pp. 5-6).

No decorrer do desenvolvimento das fases da ONHB, já destacadas, os professores orientadores das equipes se incumbem da mediação com os alunos na resolução das tarefas disponibilizadas no site do evento pela organização. Meneguello (2012, p. 2), em entrevista explica como se dá esse processo:

[...] deixamos diversos documentos originais - em formato digital disponíveis para esses alunos e professores. Em História, isso é valioso para demonstrar a importância de se trabalhar com fontes originais. Além disso, selecionamos materiais, como pesquisas e artigos, que são o que há de mais recente nos temas apresentados. Eles passam a ter contato com o melhor que é produzido dentro da academia e tornam-se uma espécie de "mini-historiadores".

Negócio e Lima-Neto (2018, p. 242) enfatizam a importância disso: "Esse banco de dados é relevante, já que possibilita aos docentes utilizar o material disponível fora do período 
competitivo, seja na sala de aula, seja para ressignificar suas avaliações ou apenas para aprendizado próprio".

Da mesma forma que as equipes, nas finais do evento, na Unicamp, os professores também são premiados com medalhas e com certificados de desempenho e de participação. Meneguello (2012, p. 2) considera que: “A premiação de professores tem vários significados, tanto do ponto de vista pessoal quanto para a formação profissional, visando que esses professores instiguem seus alunos a continuarem competindo nas próximas edições”. A coordenadora da ONHB realçou que, apesar de não haver uma relação direta das olimpíadas científicas com indicadores como o Índice de Desenvolvimento da Educação Básica (IDEB) e o Programa Internacional de Avaliação de Estudantes (PISA), há um aumento do nível de estudo em geral nas instituições que se dedicam a esses eventos.

Endossando as palavras de Meneguello, Marcelo Firer, quando diretor do Museu Exploratório de Ciências da Unicamp, na abertura da $4^{\mathrm{a}} \mathrm{ONHB}$, em 2012, estimou que os participantes dedicam, em média, quinze horas por semana para a resolução das fases on line. Ressaltou ainda que a ONHB é um processo de aprendizagem que supera o seu caráter de competição, pois não tem como foco o que os estudantes sabem sobre História, mas na capacidade destes aprenderem ao longo da Olimpíada (Firer, 2012).

$\mathrm{Na}$ elaboração das questões, ao serem apresentadas pesquisas realizadas nas Universidades, a ONHB possibilita uma aproximação entre os saberes acadêmico e escolar. Nesse sentido, a ONHB, por intermédio das múltiplas atividades realizadas em grupo sob a mediação dos docentes, oportuniza aos estudantes uma compreensão mais ampla da sociedade despertando o interesse para os fatos do cotidiano, logo, desenvolvendo uma consciência histórica, ou seja “[...] ampliação da experiência do passado humano, um aumento de competências para a interpretação histórica dessa experiência e reforço da capacidade de inserir e utilizar interpretações históricas no quadro de orientação da vida prática" (Rüsen, 2007, p. 110). Logo, o ensino e a aprendizagem dos conteúdos históricos devem ser essenciais para a orientação da vida prática, instruindo os sujeitos no seu tempo.

Retomando às observações feitas pelo professor Marcelo Firer (2012), acrescentamos que a aprendizagem proporcionada pela ONHB não se restringe aos estudantes participantes desse evento, mas também é extensiva aos professores de História envolvidos nessa atividade. Tais aprendizagens evidenciam o fato de que a escola não é apenas o lugar onde discentes 
obtêm conhecimentos "transmitidos" pelos docentes de maneira sistematizada nas disciplinas. Ao destacarmos isso, estamos mencionando um processo de formação permanente de professores que transcende os chamados cursos de "reciclagem", "treinamento" ou "capacitação" para professores. Nesse sentido, Imbernón (2009, 2010, 2011) critica os modelos de formação docente, ainda predominantes, que visam solucionar problemas genéricos, uniformes e padronizados. Para ele,

Este tratamento da formação como um problema genérico gerou um sistema de formação padrão baseado num modelo de treinamento. Muitos professores estão habituados a participar de cursos e seminários nos quais o ministrante é um expert que estabelece o conhecimento e o desenvolvimento das atividades. Num curso ou numa sessão de "treinamento", os objetivos e os resultados esperados estão claramente especificados e costumam acrescentar em termos de conhecimento (por exemplo, explicar os princípios da aprendizagem significativa) ou de desenvolvimento de habilidades (por exemplo, os participantes mostrarão que sabem utilizar na discussão de classe questões sem um esquema estabelecido) (Imbernón, 2009, p. 50).

Ao contrário dos modelos de formação que seguem uma padronização, o autor em tela sugere um outro tipo que se opere permanentemente a partir das situações problemáticas dos professores, e que supere o individualismo, adote o trabalho colaborativo, considere a comunidade, crie espaços de formativos nas escolas e assuma o desenvolvimento das atitudes e das emoções (Imbernón, 2009, 2010, 2011).

Nesse aspecto, importa salientar que as questões e as tarefas propostas pela ONHB envolvem um conjunto de atividades - refinamento das pesquisas na Internet, leitura e interpretação de gêneros textuais diversos escritos e não-escritos, entrevistas, observação participante, registros escritos, orais e visuais - superando as discussões meramente conteudistas que, não raro, ainda ocorrem no cotidiano das aulas de História, embora não apenas nesta disciplina. Podemos afirmar que os alunos e professores passam a ter contato com várias interpretações, sendo o conflito entre estas "uma riqueza do debate própria do espaço público, oposta ao 'vale-tudo' e ao 'vale somente uma coisa', autocentrados, que encaramos como esvaziamentos da reflexão" (Silva \& Guimarães, 2012, p. 9).

Desse modo, conforme Therrien, Azevedo e Lacerda (2016), o processo de educar gera uma constituição e "re-constituição" criativa de si e do mundo social. Esses pesquisadores 
observam que, no processo educativo, ocorrem transformações de um sujeito convivendo com outros sujeitos, pois a intersubjetividade condiciona as implicações dos encontros. Assim,

[...] a expressão educar revela a constituição de sujeitos [grifo dos autores], portanto o desenvolvimento de identidades [grifo dos autores] de sujeitos e, ao mesmo tempo, de sociedade, na dialética do processo de individualização e de socialização. Como prática profissional, suscita o desafio de produzir aprendizagem [grifo dos autores] (Therrien; Azevedo \& Lacerda, 2016, p. 191).

Na elaboração das provas da ONHB, os organizadores do evento trabalham no sentido de alargar a concepção de fonte histórica de modo a suscitar práticas interdisciplinares. Em todas as fases, os estudantes discutem a História a partir de documentos escritos (matérias de jornais, panfletos, cordéis, obras literárias e textos oficiais) e visuais (fotografias, pinturas, xilogravuras e charges), além de valorizar a História Oral e o patrimônio histórico material e imaterial como fontes para a reconstrução de memórias históricas, públicas e privadas. Dessa forma, a ONHB não disponibiliza as questões sob a perspectiva de uma História tradicional, cronológica, linear e disciplinar. Logo, a Olimpíada adere às novas concepções de pesquisa histórica, demonstrando, na prática, uma observação feita por Pinsky (2015, p. 7):

Os currículos escolares e o próprio trabalho em sala de aula têm procurado acompanhar o desenvolvimento dos estudos históricos. A velha História de fatos e nomes já foi substituída pela História Social e Cultural; os estudos das mentalidades e representações estão sendo incorporados; pessoas comuns já são reconhecidas como sujeitos históricos; o cotidiano está presente nas aulas e o etnocentrismo vem sendo abandonado em favor de uma visão mais pluralista.

Ao examinar questões das provas da ONHB, Costa Júnior (2017) evidencia o caráter crítico e reflexivo dos seus conteúdos, conduzindo-nos a perceber a contestação que esse evento, embora seja uma competição e receba críticas por esse fato, vai de encontro à educação bancária, cuja tarefa do docente é "encher" os educandos de conteúdo, como esclarece Freire (2012). Para esse autor, “Quanto mais vá 'enchendo’ os recipientes com seus 'depósitos', tanto melhor educador será. Quanto mais se deixem docilmente 'encher', tanto melhores educandos serão" (Freire, 2012, p. 63). Freire defende ainda que o docente não apenas ensina, mas também aprende ao exercer esse ato, haja vista ser um sujeito inconcluso e que, ao ter consciência dessa inconclusão entra num permanente movimento de busca. "Na verdade, seria uma contradição se, inacabado e consciente do inacabamento, o ser humano não 
se inserisse em tal movimento. É nesse sentido que, para mulheres e homens, estar no mundo significa estar com o mundo e com os outros" (Freire, 2008, pp. 57-58).

A resolução das questões suscita uma busca pelo conhecimento ou pelo aprofundamento do já existente. Exige que os docentes troquem ideias com colegas da sua instituição e de outras, e acessam novas teorias, fontes, artigos, livros e autores. Com isso, a tendência é uma ampliação de saberes que não são apenas acadêmicos, mas adquiridos nas práticas e nas experiências com os outros (Pimenta, 2009; Tardif, 2011). Pari passu ao acesso a novos conhecimentos, professores e alunos devem socializá-los, embora saibamos que há casos em que essa coletivização se dá timidamente em função da concorrência entre as equipes. Apesar disso, não podemos deixar de acreditar na possibilidade da socialização entre o "eu" e o "outro", como observa Therrien, Azevedo e Lacerda (2016, p. 193):

O "outro" é necessário para a descoberta do "eu" na dialética dos confrontos. Com o outro "dialogamos", mesmo nos embates e recusas; sem o outro, permanecemos no monólogo do eu consigo mesmo, no perigoso círculo vicioso de repetir os mesmos saberes de sempre! O princípio da reflexividade crítica do educador reside nesta encruzilhada: do sujeito que, em situação de práxis, confronta seus saberes e concepções pela ação comunicativa de objetivação e subjetivação, aberta e honesta, com disposição para novas percepções e compreensões de saberes. No oposto da ação dialógica, reside o monólogo normativo e prescritivo, que, por não reconhecer o "outro", não transforma.

O caráter social dos saberes docentes é realçado por Tardif (2011), pois são partilhados por um grupo de agentes que trabalham numa mesma organização. Ademais, "um professor nunca define sozinho e em si mesmo o seu próprio saber profissional. Ao contrário, esse saber é produzido socialmente, resulta de uma negociação entre diversos grupos" (Tardif, 2011, pp. 12-13). Para ele, "Ensinar é agir com outros seres humanos [...] Portanto, o saber não é uma substância ou um conteúdo fechado em si mesmo; ele se manifesta através de relações complexas entre professor e seus alunos" (Tardif, 2011, p. 13).

Ocorre, dessa forma, no decorrer das fases da ONHB, um processo de mediação, definido por Libâneo (2011, p. 92) como "o conjunto de atividades do professor e dos alunos sob a direção do professor, visando à assimilação ativa pelos alunos dos conhecimentos, habilidades e hábitos, atitudes, desenvolvendo suas capacidades e habilidades intelectuais"; e por Therrien, Azevedo e Lacerda (2016, pp. 194-195), como o encontro de sujeitos que se 
manifesta "nos contextos das interações intersubjetivas no chão da sala de aula, onde o docente encontra o desafio de transformar pedagogicamente os saberes dos conteúdos a ensinar, produzindo sentidos e significados com seus alunos aprendizes”.

Em várias situações, a resolução das questões da ONHB leva o professor orientador a refazer e/ou refletir suas concepções históricas e de didática, o que nos remete à visão freireana de professor pesquisador: "Faz parte da natureza da prática docente a indagação, a busca, a pesquisa. O que se precisa é que, em sua formação permanente, o professor se perceba e se assuma, porque professor, como pesquisador" (Freire, 2011, p. 30).

Os professores e alunos, ao estudarem juntos os diferentes materiais oferecidos nas questões (documentos históricos, textos acadêmicos e literários, charges, pinturas), geralmente de caráter interdisciplinar, algumas versões dos acontecimentos, encontradas em livros didáticos, são questionadas por outras obras ou documentos históricos. Além disso, o acesso a novas pesquisas, a ampliação do conceito de fonte e de documento histórico, geram outras interpretações históricas, levando os sujeitos envolvidos a constatar não apenas a sua "incompletude" do conhecimento, mas a transitoriedade e a intencionalidade dos fatos e da escrita da História.

A História é uma ciência viva, não apenas no cotidiano dos cidadãos, mas também nas Universidades e centros de pesquisas, onde se verifica, hoje, uma impressionante produção de novos conhecimentos que, a par de seu valor intrínseco, de natureza humanística, têm sido instrumentos úteis na busca de respostas para a resolução de problemas sociais coletivos da maior importância (Bittencourt, 2011).

Certamente por perceberem isso, os organizadores das atividades propostas pela ONHB se interessam que os envolvidos nesse evento, docentes e discentes, constatem as continuidades e descontinuidades dos fatos, e ainda, apreendam as relações entre o passadopresente-futuro, necessárias para enfrentar os problemas impostos pelo mundo contemporâneo. Ou seja, as equipes devem compreender que "O passado é construído a partir do presente, que seleciona aquilo que, a seus olhos, é histórico, isto é, precisamente aquilo que, no passado, desenvolveu-se para produzir o presente. [...] Ora, o futuro nasce do presente" (Morin, 2010, pp. 12-13).

Ao refletirem sobre o ensino de História no século XXI, Silva e Guimarães (2012, pp. 125-126) assim se posicionam: 
O professor de história e os seus alunos podem e devem trabalhar com livros didáticos, livros não didáticos, filmes de ficção e documentários, histórias em quadrinhos, música erudita e música popular, paisagens e edificações, objetos tridimensionais, diferentes modalidades do imaginário social, computadores, jogos etc. Tudo é história, o que amplia ao infinito o leque de temas e problemáticas de conhecimentos a serem estudados e de materiais de época (documentos históricos) para discussão.

O estudo desenvolvido por Souza e Costa (2016) sobre uma experiência vivida por ambos com os seus estudantes na ONHB é um exemplo do que observam Silva e Guimarães (2012). Os autores analisaram uma tarefa solicitada pela organização do evento e realizada por estudantes do Ensino Médio Integrado $^{2}$ de uma instituição de Educação Profissional e Tecnológica. A atividade envolvia as transformações do mundo do trabalho e o uso da metodologia da História Oral. As equipes entrevistaram sujeitos cujas profissões estão em processo de extinção, em virtude do desenvolvimento tecnológico. Além disso, visitaram antigos lugares de trabalho que perderam a importância de outrora. Os contatos com os entrevistados e com os lugares de memória do trabalho deram aos alunos uma dimensão sobre as metamorfoses do mundo do trabalho que, talvez, não tivessem na sala de aula, mesmo num curso de formação profissional. Da mesma forma, os professores orientadores das equipes dessa instituição também tiveram acesso a conhecimentos da história local que provavelmente não teriam se não fossem motivados pela tarefa exigida pela ONHB. Terminada a experiência, os autores concluíram que:

[...] no caso específico da Educação Profissional, consideramos que a ONHB colabora para a formação de estudantes-cidadãos-trabalhadores e estimulam a práxis pedagógica dos educadores ao desenvolver metodologias que enfatizam a construção de estratégias, a criatividade, a iniciativa pessoal, o trabalho coletivo e a autonomia advinda da confiança na capacidade de enfrentar desafios (Souza \& Costa, 2016, p. 84).

A preocupação do ensino de História como questões que vão além dos livros didáticos ou de um currículo oficial, demonstra o caráter humanizador dessa disciplina. Assim, concordamos com Lima e Medeiros (2015, p. 15), no sentido de que o ensino de História “[...] não pode se submeter à mera preparação para o ingresso no ensino superior. Mas, deve, sobretudo, atender às necessidades imediatas da juventude, que tem ingressado cada vez mais cedo no mercado de trabalho". No Ensino Médio Integrado, inserir a dimensão do trabalho

${ }^{2}$ O Ensino Médio Integrado à Educação Profissional é uma das formas de oferta dos Cursos Técnicos de Nível Médio nas instituições de Educação Profissional e Tecnológica no Brasil. Essa forma foi criada pelo Decreto $\mathrm{n}^{\circ}$ 5.154/2004, no governo do então Presidente Luis Inácio Lula da Silva. 
como princípio educativo é condição essencial para que estudantes e professores percebam-se como sujeitos históricos num processo contínuo de ensino/aprendizagem. Por conseguinte, ao se inserir no mundo do trabalho, os alunos precisam entender os pressupostos históricos, sociais, políticos e econômicos que envolvem sua ação profissional (Lima \& Medeiros, 2015).

Até aqui salientamos a importância da ONHB para a formação continuada de professores, na medida em que estes intercambiam conhecimentos com os seus pares e com os seus alunos na resolução de problemas presentes nas provas e tarefas propostas pelo evento. Entretanto, no decorrer dos anos, sua organização tem se preocupado com essa formação e realizado cursos voltados para docentes. São exemplos disso a conferência ministrada, na Unicamp, no mesmo horário em que os estudantes estão respondendo a prova discursiva em um outro local; e a promoção de um curso presencial, durante cinco dias, para os professores orientadores das equipes melhores classificadas nas fases virtuais nos estados da federação e nas cinco regiões brasileiras.

Além dessas ações, a partir da $5^{\mathrm{a}}$ edição da ONHB, em 2013, o Departamento de História da Unicamp passou a promover cursos de formação continuada à distância, inicialmente para os docentes orientadores inscritos na ONHB, e, posteriormente, estendido a todos os interessados, mediante pagamento de uma taxa de inscrição. Inicialmente, o curso possuía uma carga horária de 42 horas, no entanto, após sugestões dos professores orientadores participantes, a partir de 2017 a passou a ser de 60 horas, e envolve atividades de leitura, escrita, debate e o acompanhamento de tutores on line. As temáticas dos seis cursos ofertados entre 2013 e 2019 estão dispostas na Tabela 3:

Tabela 3

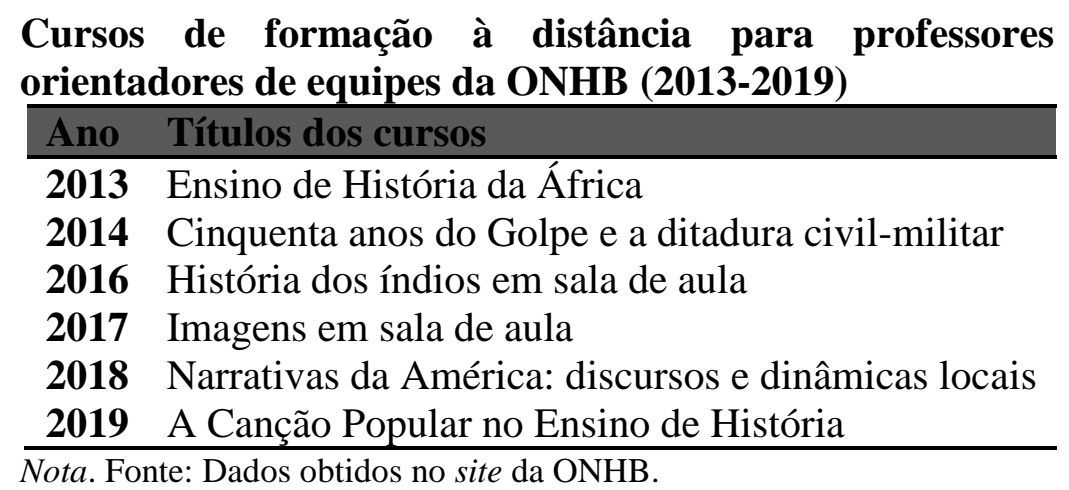

Percebe-se, nos títulos dos cursos, a atenção dada às metodologias para o ensino de História, a exemplo do uso didático de imagens e de composições musicais. Predominam 
cursos relacionados a temas pouco explorados em sala de aula, como a História da África, dos povos indígenas e da América, assuntos presentes nos livros didáticos, mas ainda carentes de aprofundamento. Evidencia-se também a postura política desses cursos, sobretudo do que aborda os cinquenta anos do golpe militar no Brasil, fato cuja existência era inquestionável para a maioria dos brasileiros, mas que, no final da segunda década do século XXI, tem sido refutado pelo governo federal e grupos de extrema-direita que lhe dão apoio. Assim, compreendemos que, para os organizadores da ONHB, ensinar vai além de transferir conhecimentos, mas por em prática uma pedagogia crítica "que faça da opressão e de suas causas objeto da reflexão dos oprimidos, de que resultará o seu engajamento necessário na luta por sua libertação, em que esta pedagogia se fará e refará” (Freire, 2012, p. 35).

\section{Considerações finais}

Neste artigo, apresentamos a ONHB como uma importante estratégia para a formação permanente de professores de História, como também para o desenvolvimento de meios para ensino dessa disciplina. Para nós, a ONHB amplia conhecimentos, inova as práticas dos professores de História, desenvolve a criatividade dos jovens que dela participa, permite a iniciativa pessoal, o trabalho coletivo e a autonomia.

No decorrer das fases da ONHB, é possível uma reorganização do papel do professor, passando este a ser um estimulador da pesquisa coletiva e colaborativa, abdicando, portanto, da função de detentor e centralizador do processo do ensino-aprendizagem. É possível afirmar que a ONHB proporciona o rompimento do individualismo da formação e viabiliza espaços de socialização do conhecimento em três esferas: entre os professores e os seus pares; entre os professores e os seus alunos; e entre os alunos.

Entretanto, temos que reconhecer que, na prática, essa cultura não é algo simples e fácil de ser realizada, pois exige que docentes e discentes superem o caráter de competitividade que tem uma Olimpíada, seja na forma de medalhas, certificados, menções honrosas ou, em alguns casos, de uma sonhada passagem aérea para Campinas com o objetivo de participar da final do evento. Vale destacar que a competição entre equipes tem sido constantemente evitada pelos promotores do evento.

A Comissão Organizadora da ONHB busca atenuar a competitividade, recusando-se, por exemplo, a divulgar um ranking, estimulando a cooperação em equipe e trabalhando diferentes linguagens. A definição, por exemplo, do que é "mais pertinente" na resposta de 
uma questão é subjetiva e nossa experiência mostrou, muitas vezes, que os estudantes deixaram de buscar a pertinência da questão - na perspectiva deles - para buscar "como a comissão enxerga a pertinência”, afinal, é uma competição.

Os resultados das premiações nas edições da ONHB, infelizmente, refletiram também que ainda persiste uma grande desigualdade de aprendizagens entre os estudantes de escolas privadas e públicas. O bom desempenho de várias equipes dos Institutos Federais impediu, de certa forma, que essa disparidade não seja maior. Essa assimetria foi percebida, inclusive, na dificuldade de deslocamento para disputar a fase final em Campinas por parte das equipes com menor poder aquisitivo.

Não obstante, o nosso entendimento é que existe uma possibilidade de substituir uma relação predatória, classificatória e meritocrática de competição, e desenvolver sentimentos de pertencimento e colaboração entre os participantes, logo, sem perder a ludicidade de um desafio intelectual. No nosso caso, acreditamos que temos alcançado êxito nesse aspecto.

Nossa avaliação positiva quanto à ONHB não se ampara apenas na obtenção de medalhas de ouro, prata, bronze e menções honrosas que conseguimos nas nossas participações em dez edições dessa Olimpíada, mas ainda ao trabalho em grupo desenvolvido com colegas professores e equipes de alunos. Somado a isso, há um enorme ganho em termos de formação continuada e no crescimento pessoal dos estudantes, haja vista que estes interagem com os colegas, autoavaliam-se, superam os conflitos que ocorrem entre os membros das equipes e entre estas.

Do ponto de vista do processo de ensino-aprendizagem, nossa avaliação é igualmente favorável, visto que esses alunos passam a adquirir conhecimentos que transcendem os livros didáticos e aprendem história através de pesquisas de campo, leituras de documentos (alguns de acesso apenas a pesquisadores), análise de imagens, dentre outros meios que permitem uma aprendizagem diferente da "mesmice" a que estão acostumados.

\section{Referências}

Bittencourt, C. (2011). Ensino de história: fundamentos e métodos. 4. ed. São Paulo: Cortez.

Conselho Nacional de Desenvolvimento Científico e Tecnológico (2015). Olimpíadas científicas. Recuperado de: http://cnpq.br/olimpiadas-cientificas/\#void

Conselho Nacional de Desenvolvimento Científico e Tecnológico. (2019) Chamada CNPq/MCTIC $N^{o} \quad 13 / 2019 \quad$ - Olimpíadas Científicas. Recuperado de 
http://cnpq.br/chamadas-

publicas?p_p_id=resultadosportlet_WAR_resultadoscnpqportlet_INSTANCE_0ZaM\& filtro $=$ encerradas $\&$ startPage $=2 \&$ buscaChamada $=\& a n o=$

Costa, J. G. B., Jr. (2017). A Olimpíada Nacional em História do Brasil (ONHB) e o Ensino Médio Integrado no IFRN (Dissertação de Mestrado). Instituto Federal de Educação, Ciência e Tecnologia do Rio Grande do Norte, Mossoró, RN, Brasil.

Chizzotti, A. (2000) Pesquisa em Ciências Humanas e Sociais. 4. ed. São Paulo: Cortez.

Dubet, F. (2004) O que é uma escola justa? Cadernos de Pesquisa, 34(123), 539-555. Recuperado de https://www.scielo.br/pdf/cp/v34n123/a02v34123.pdf

Firer, M. (2012, agosto 20). Cerimônia de lançamento da $4^{a}$ ONHB. [Arquivo de vídeo] Recuperado de link: http://www.youtube.com/embed/ElJFh4kHv4g

Freire, P. (2011). Pedagogia da autonomia: saberes necessários à prática educativa. São Paulo, Paz e Terra.

Freire, P. (2012). Pedagogia do oprimido. Rio de Janeiro: Nova Fronteira.

Imbernón, F (2009). Formação permanente do professorado: novas tendências. São Paulo: Cortez.

Imbernón, F. (2010). Formação continuada de professores. Porto Alegre: Artmed.

Imbernón, F. (2011) Formação docente e profissional: formar-se para a mudança e a incerteza. 9. ed. São Paulo: Cortez.

Libâneo, J. C. (2011). Didática e trabalho Docente: a mediação didática do professor nas aulas. In: Libâneo, J. C.; Suanno, M. V. R.; Limonta, S. V (Org.). Concepções e práticas de ensino num mundo em mudança: diferentes olhares para a didática (pp. 85-100). Goiânia: CEPED/Editora PUC Goiás.

Lima, A. C. S., \& Medeiros, O. M., Neta. (2015). O ensino de História no Curso Técnico Integrado de Turismo - CEFETRN/IFRN - campus Natal/Central (2005-2011). Revista Brasileira de Educação Profissional e Tecnológica, 1(8), 11-33. Recuperado de http://www2.ifrn.edu.br/ojs/index.php/RBEPT/article/view/3217/1253 doi: 10.15628/rbept.2015.3217

Meneguello, C. (2011). Olimpíada Nacional em História do Brasil: uma aventura intelectual? História Hoje, 5(14), 1-14, Recuperado de https://anpuh.org.br/index.php/revistahistoria-hoje/rhh-volumes-anteriores/item/2575-volume-5-n-14

Meneguello, C. (2015, outubro). Com Ciência: revista eletrônica de jornalismo científico. Recuperado de http://www.comciencia.br/comciencia/handler.php?section=8\&tipo=entrevista\&edicao $=117$

Miranda, A. R. A. (2015). Projeto “Olimpíada Nacional em História do Brasil na E.E.F.M. Tenente Mário Lima": educação histórica em prática. In: Paulo, A. F. et al. (Org.). Ensino de História na educação básica: reflexões, fontes e linguagens (pp. 75-94). Fortaleza: EdUECE, 2015.

Morin, E. (2010). Para onde vai o mundo. 2. ed. Petrópolis, RJ: Vozes. 
Negócio, P. A. F., \& Lima-Neto, V. (2018). A Olimpíada Nacional em História do Brasil (ONHB) e suas contribuições para o ensino de Língua Portuguesa. In: Tamanini, P.A. (Org.). Proposituras: ensino e saberes sob um enfoque interdisciplinar (pp. 229-245). São Carlos: Pedro \& João Editores.

Olimpíada Nacional em História do Brasil. (2020). Edições. Recuperado de https://www.olimpiadadehistoria.com.br/paginas Acesso em: 03 jun. 2020.

Olimpíada Nacional em História do Brasil. (2019). Inscrições para 12ª Olimpíada de História serão abertas dia 3 de fevereiro. Recuperado de https://www.olimpiadadehistoria.com.br/noticias/ler/168

Pimenta, S. G. (2009). Formação de professores: identidade e saberes da docência. In: Pimenta, S. G. Saberes pedagógicos e atividade docente (7a ed., pp. 15-34) São Paulo: Cortez.

Pinsky, C. B. (2015). Introdução. In: PINSKY, C. B. Novos temas nas aulas de História. (2a ed., pp. 7-12). São Paulo: Contexto.

Quadros, A., Fátima, Â., Martins, D., Silva, F., Freitas-Silva, G., Aleme, H., Oliveira, S., Andrade, F., Tristão, J., \& Santos, L. (2013). Ambientes colaborativos e competitivos: o caso das olimpíadas científicas. Revista de Educação Pública, 22(48), 149-163. doi: https://doi.org/10.29286/rep.v22i48.852

Rezende, F., \& Ostermann, F. (2012). Olimpíadas de ciências: uma prática em questão. Ciência \& Educação, 18(1), 245-256. Recuperado de https://www.scielo.br/pdf/ciedu/v18n1/15.pdf

Rodrigo, E. (2012). Olimpíadas científicas, jogos sem perdedores. In: Revista Pré-Univesp, 23(25). Recuperado de https://eniorodrigo.wordpress.com/2013/02/25/olimpiadascientificas-jogos-sem-perdedores/

Rüsen, J. (2007). História viva: teoria da História III: formas e funções do conhecimento histórico. Brasília: UNB.

Souza, F. C. S., \& Costa Jr., J. G. B. (2016). A Olimpíada Nacional em História do Brasil (ONHB) como prática pedagógica no ensino médio integrado do IFRN. Revista História Hoje, 5(10), 66-86. Recuperado de https://rhhj.anpuh.org/RHHJ/article/view/273

Silva, M., \& Guimarães, S. (2012). Ensinar História no século XXI: em busca do tempo estendido. 4. ed. Campinas: Papirus.

Tardif, M. (2011). Saberes docentes e formação profissional. 12. ed. Petrópolis: Vozes.

Therrien, J.; Azevedo, M. R. C., \& Lacerda, C. R. (2017). A racionalidade pedagógica nos processos de mediação à produção de sentidos e de aprendizagem aos saberes. Educação \& formação, 2(6), 186-199. Recuperado de https://revistas.uece.br/index.php/redufor/article/view/166 
José Gerardo Bastos Costa Júnior Licenciado em História, mestre em Ensino (UERN/IFRN/UFERSA). http://orcid.org/0000-0002-8428-2281. Instituto Federal de Educação, Ciência e Tecnologia do Rio Grande do Norte (IFRN), Campus Mossoró, Brasil.

Francisco Das Chagas Silva Souza. https://orcid.org/0000-0002-9721-9812. Doutor em Educação (UFRN/Brasil), pós doutor em Educação (UFF/Brasil), professor do Instituto Federal de Educação, Ciência e Tecnologia do Rio Grande do Norte. Professor dos Programas de Pós-Graduação em Educação Profissional (Doutorado), do Programa de Pós-Graduação em Educação Profissional e Tecnológica (Mestrado Profissional em Rede Nacional) e do Programa de Pós-Graduação em Ensino (POSENSINO). 